\title{
Erratum to: The Overt Pronoun Constraint Across Three Dialects of Spanish
}

\author{
Carlos Gelormini-Lezama ${ }^{1}$ - David Huepe ${ }^{2}$. Eduar Herrera ${ }^{3}$. \\ Margherita Melloni',4,5 • Facundo Manes ${ }^{2,4,5}$ - Adolfo M. García 2,4,5,6 . \\ Agustín Ibáñez ${ }^{2,4,5,7}$
}

Published online: 30 May 2016

(C) Springer Science+Business Media New York 2016

\section{Erratum to: J Psycholinguist Res DOI 10.1007/s10936-016-9426-2}

The original version of this article unfortunately contained an error in the author affiliation. The second affiliation was submitted and published incorrectly. The affiliation is corrected with this erratum.

The online version of the original article can be found under doi:10.1007/s10936-016-9426-2.

Carlos Gelormini-Lezama carlosgelormini@yahoo.com

1 Departamento de Ciencias Sociales, Universidad de San Andrés, Vito Dumas 284, B1644BID Buenos Aires, Argentina

2 Department of Psychology, Center for Social and Cognitive Neuroscience, Universidad Adolfo Ibanez, Santiago, Chile

3 Universidad Icesi, Departamento de Estudios Psicológicos, Cali, Colombia

4 Laboratory of Experimental Psychology and Neuroscience (LPEN), Institute of Cognitive and Translational Neuroscience (INCyT), INECO Foundation, Favaloro University, Buenos Aires, Argentina

5 National Scientific and Technical Research Council (CONICET), Buenos Aires, Argentina

6 Faculty of Elementary and Special Education (FEEyE), National University of Cuyo (UNCuyo), Mendoza, Argentina

7 Centre of Excellence in Cognition and its Disorders, Australian Research Council (ACR), Sydney, Australia 